This article has been scanned by iThenticat No plagiarism detected

Volume 3, Issue 4, August 2021

p. $113-123$

\title{
THE POLICY OF ARABIZATION OF EDUCATION IN ALGERIA BETWEEN LINGUISTIC PLANNING AND SOCIAL REALITY: ARABIZATION OF HIGHER EDUCATION AS A MODEL
}

http://dx.doi.org/10.47832/2757-5403.4-3.10

Zahia DJABALLAH 1

\begin{abstract}
:
This article is concerned with research on the sociolinguistic reality in Algeria, by studying one of its issues, which is the issue of the arabization of education. And if the linguistic policy is affected and influenced by social life, then planning in arabization has a relationship with social reality. Therefore, our research aimed at studying the relationship between the applied arabization policy and the linguistic requirements of social reality. The most important results reached were the inconsistency of the applied arabization policy with the linguistic base established by the colonial authority, which continued after independence, and led to the emergence of fundamental problems, resulting from the total arabization of the basic and secondary training and some specializations in higher education. So that students in arabized disciplines largely lost control over the foreign language, which is a prerequisite for contemporary changes and for national needs that require control over bilingualism. As for those enrolled in specializations that depend on the French language, they found difficulty with the language of formation, because their basic formation was in the Arabic language.
\end{abstract}

Key words: The Policy of Arabization, Higher Education, Language Planning, Social Reality, Undergraduate Student.

\footnotetext{
${ }^{1}$ Dr. , Algiers 2 University, Algeria, zahia.djaballah@univ-alger2.dz, https://orcid.org/0000-0003-0938-922X
} 
سياسة تعريب التعليم في الجزائر بين التخطيط اللغوي والواقع الاجتماعي: تعزيب التعليم العالي نموذجان التطبا

جاب الله زهية 2

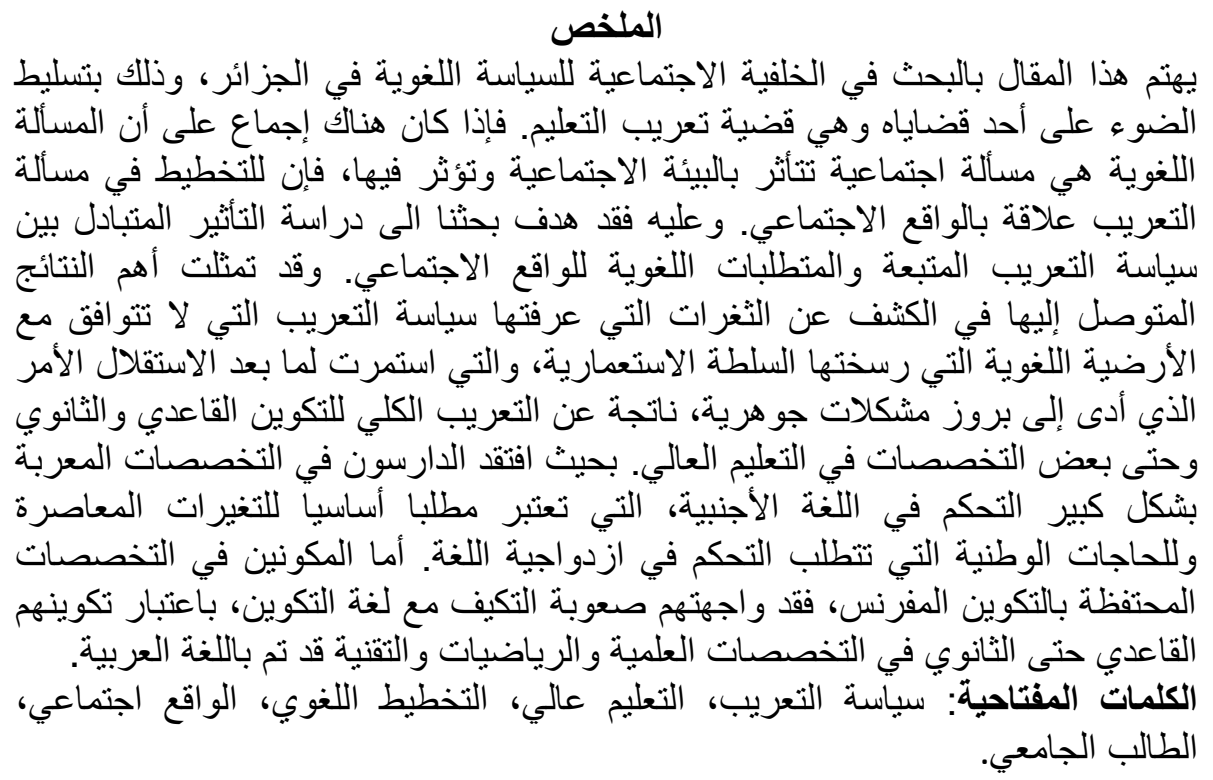

المقاَّمة:

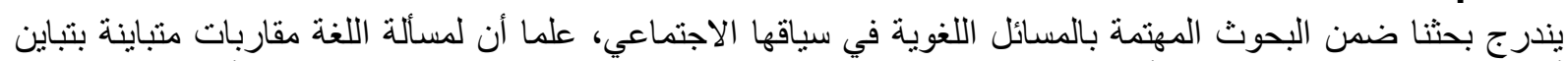

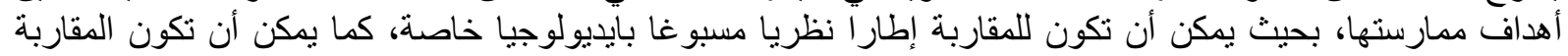

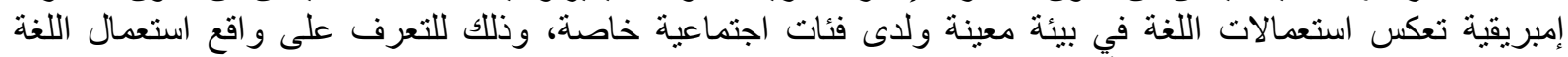

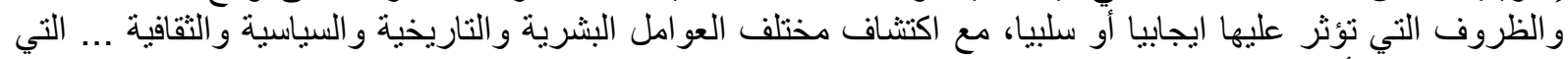

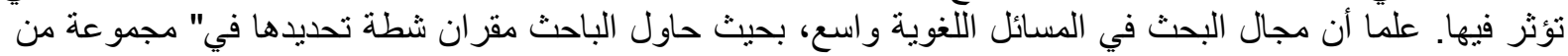

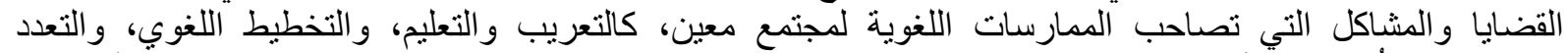

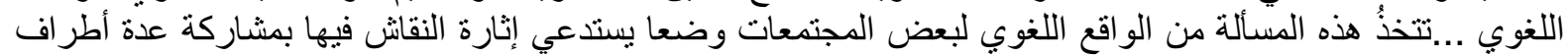

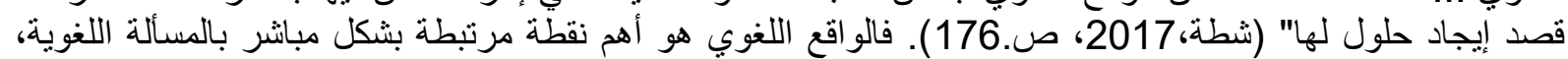

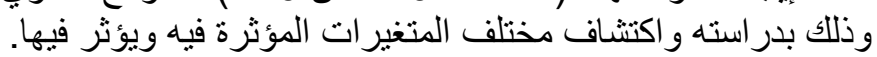

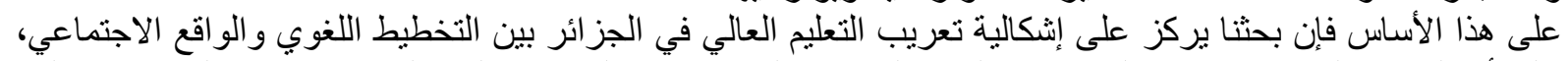

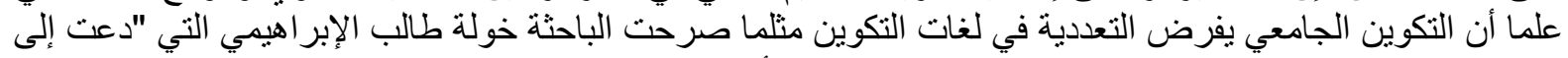

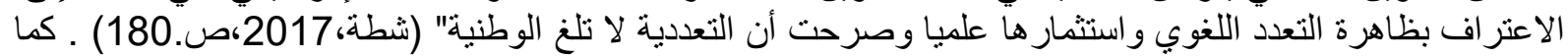

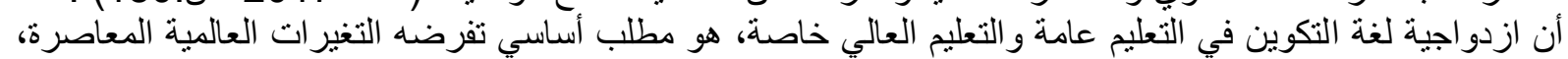

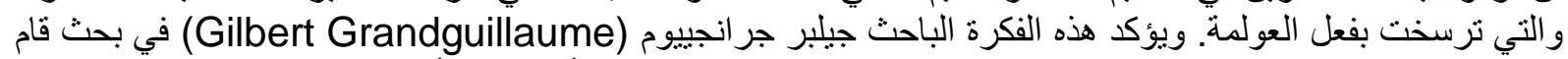

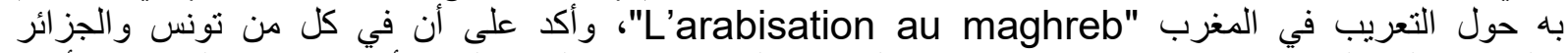

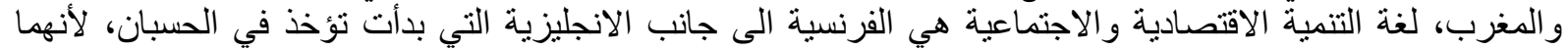

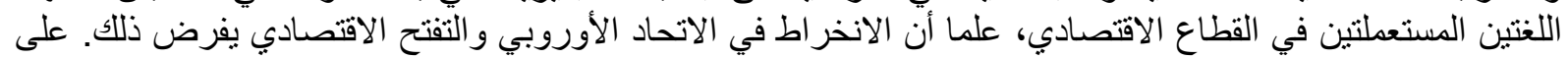

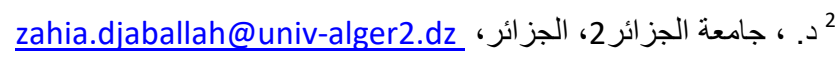


هذا الأساس فإن المخططات الإصلاحية على مستوى التعليم العالي لا يمكن أن تكون ناجعة دون الأخذ بعين الاعتبار هذا

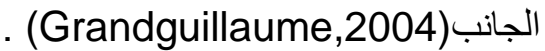
إن اهتمامنا بالبحث في مستوى الطالب الجامعي في اللغة الأجنبية، ليس الهدف منه هو التركيز على الجانب اللغوي فقط،

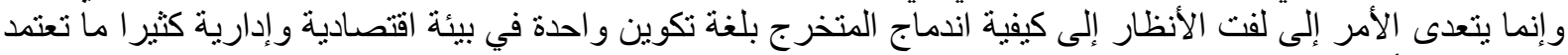

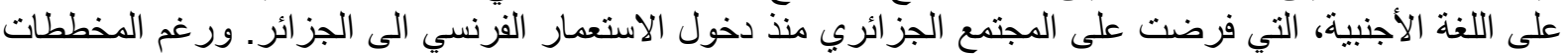

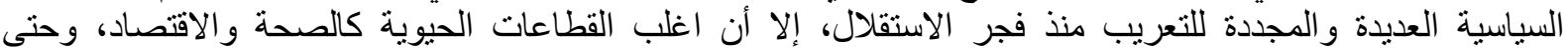

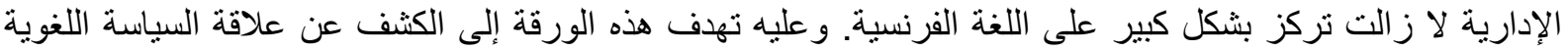

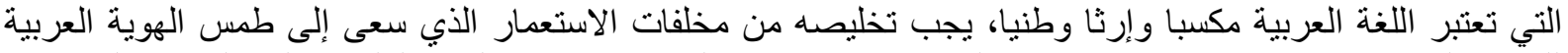

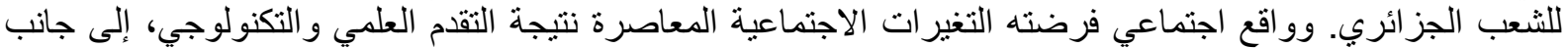

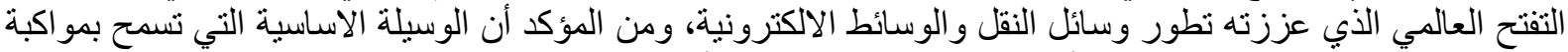

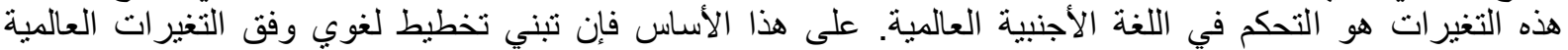

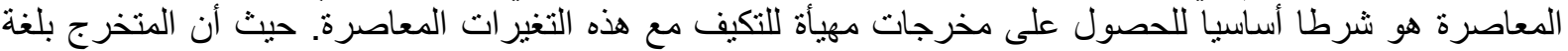

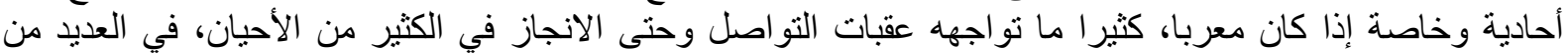

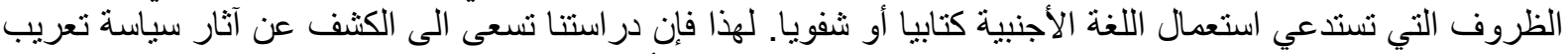

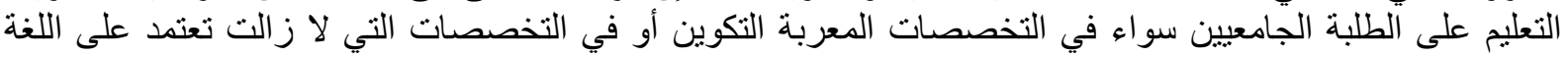

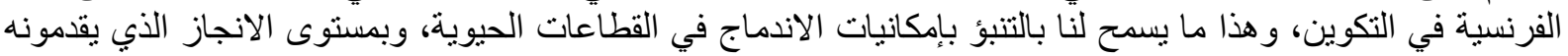

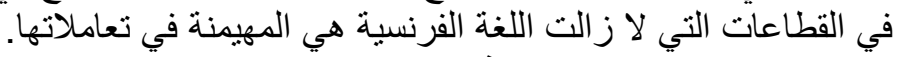

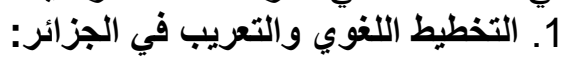

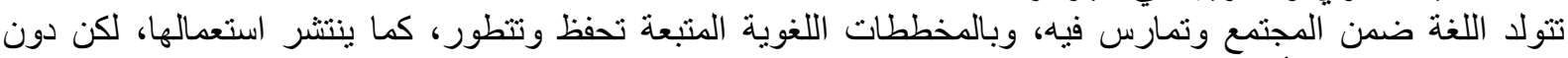

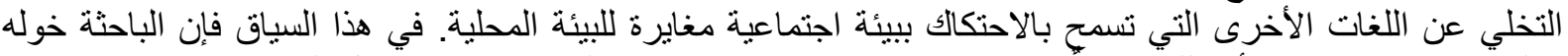

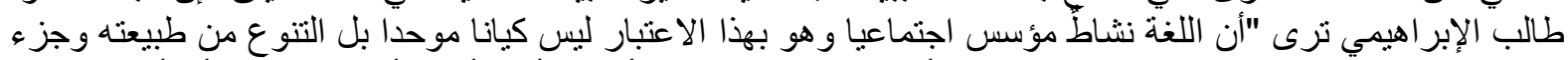

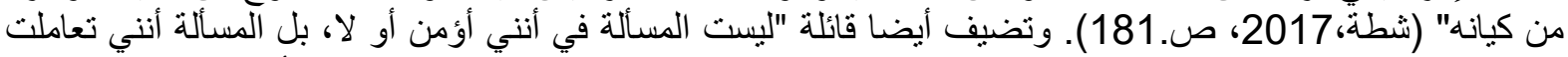

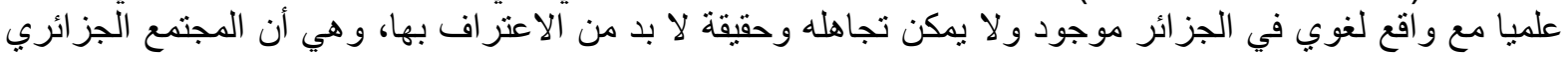

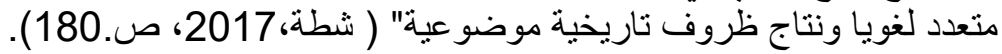

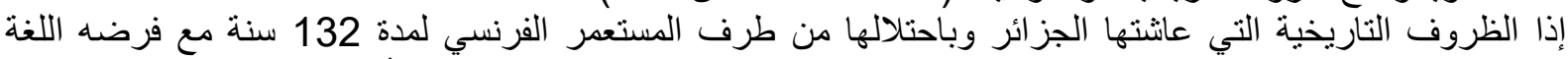

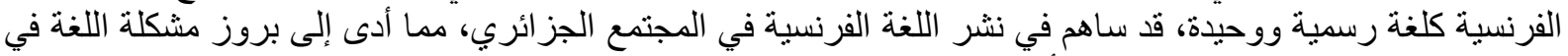

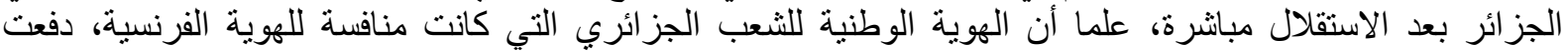

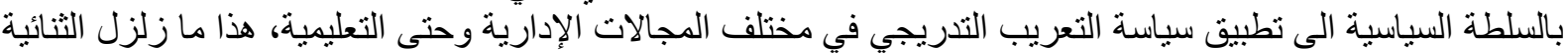

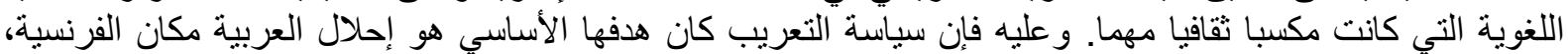

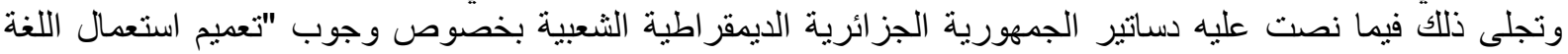

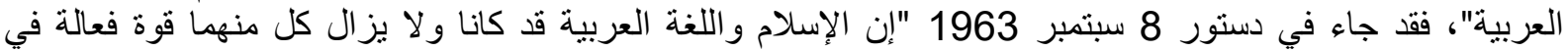

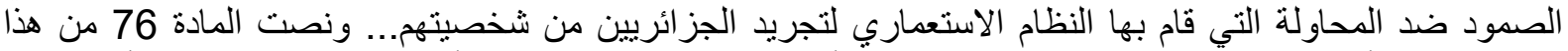

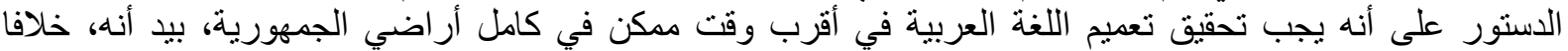

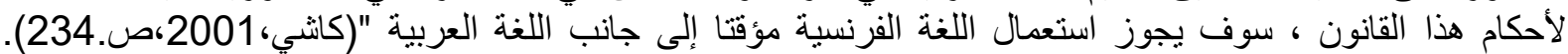
وجاء في دستور 22 نوفمبر 1976 وفي دسني دسنور 28 نوفمبر 1996 في المادة المادة3: اللغة العربية هي اللغة الوطنية

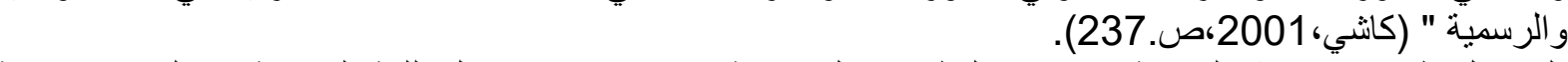
لكن هل طبقت فعلا هذه السياسة في جميع القطاعات الجزائرية؟ وما مصير استعمال اللغة الفرنسية في الجزائر خاصة

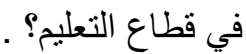
إن الباحثة خولة طالب الإبر اهيمي قد انتقدت سياسة التعريب بالجز ائر ، بحيث " ترى أنه لم يستفد التعريب أبدا من تخطيط

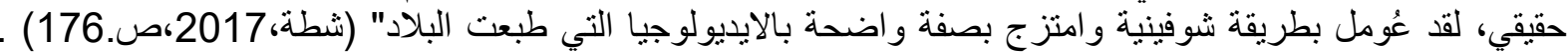

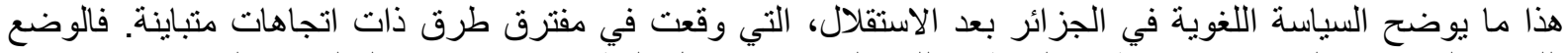

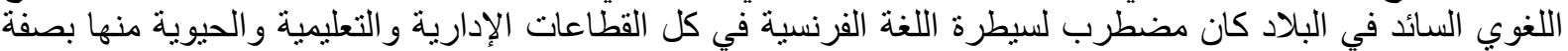

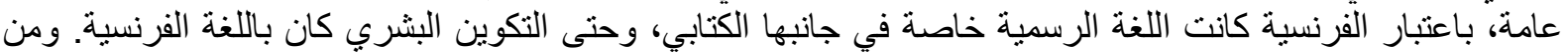

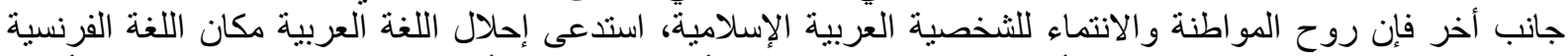

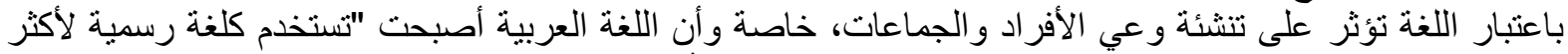

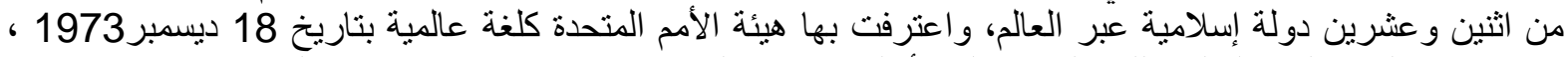

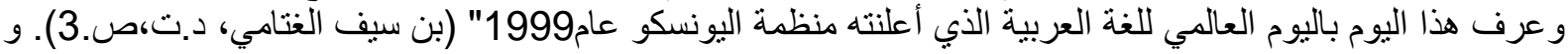

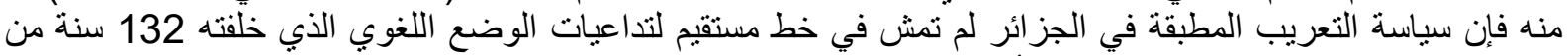

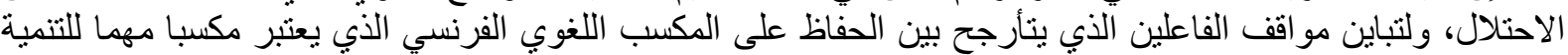




\section{THE POLICY OF ARABIZATION OF EDUCATION IN ALGERIA BETWEEN \\ LINGUISTIC PLANNING AND SOCIAL REALITY: ARABIZATION OF HIGHER EDUCATION AS A MODEL}

وللتفتح على باقي دول العالم، والموقف الثناني المشبع بروح القومية العربية الإسلامية، هذا ما أدى إلى اضطر اب الوضع

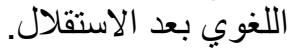

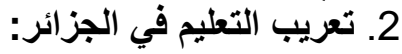
ترى الباحثة كريستيان سوريو (Christiane Souriau) في بحثها حول سياسة التعريب في الجزائر، أن أن هنالك مطلب

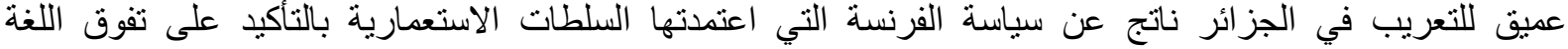

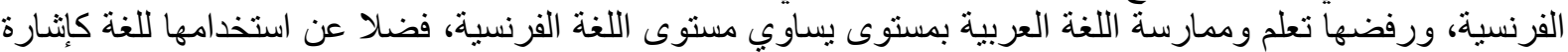

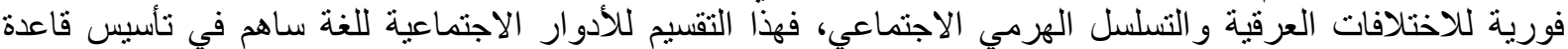

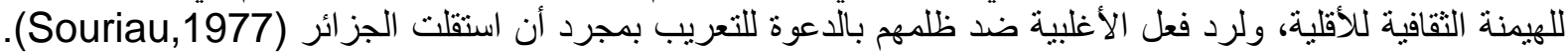

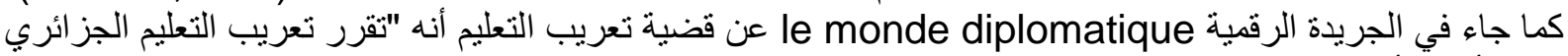

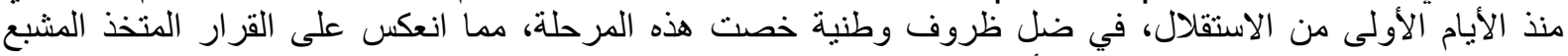

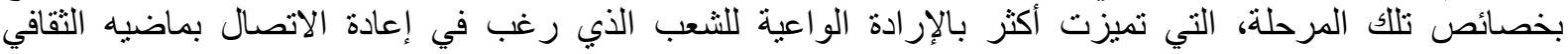

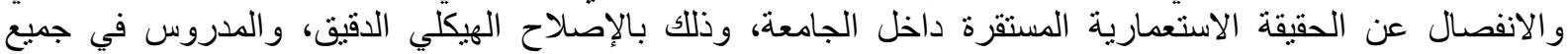
تداعياته" (1965,p.16 diplomatique, Monde).

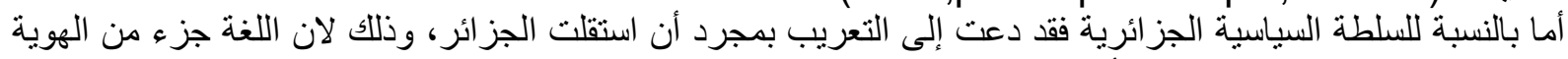

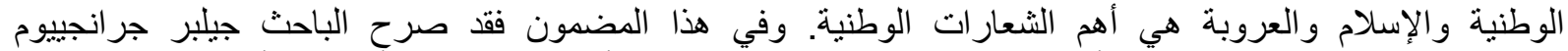

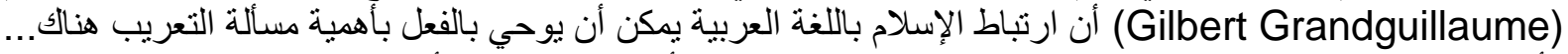

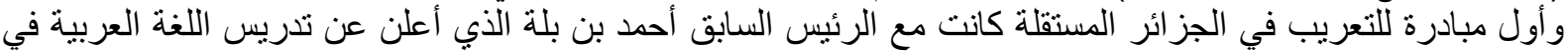

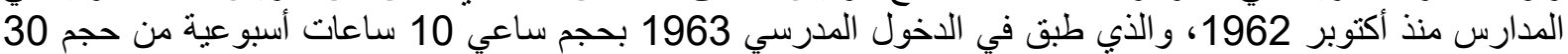

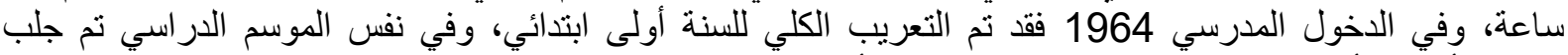

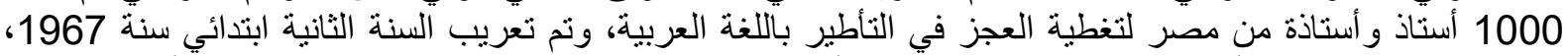
وفي سنة 1968 تم فتح أول دفعة معربة في الحقوق، وأول ليسانس في التاريخ باللغة العربية، كما تم نشر أمرية في في العية 26

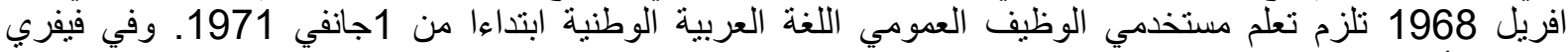

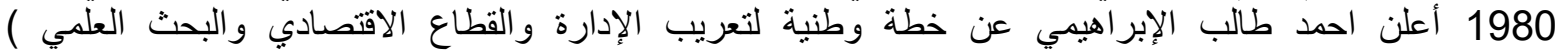
.Grandguillaume ,2004) واستمرت عمليات التعريب خاصة تعريب التعليم، بحيث في " سنة 1979 تأسست المدرسة الاساسية، وبرمج تعريب 1986 الإبـ

الأطوار الثلاثة كليا ابتداءا من 1986، وبدخول 1989/1988 نم تعريب كليا التعليم الثانوي" (Taleb)

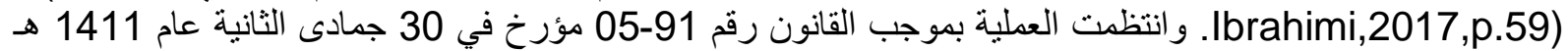

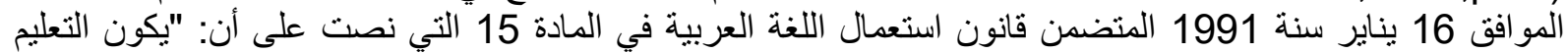

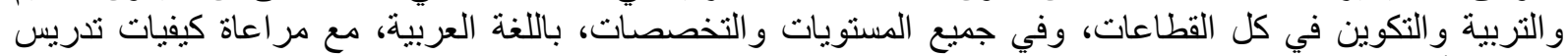
اللغات الأجنبية" (كانشي، في كل: 2001،صول252). أما بالنسبة للتعليم الجامعي فإن إصلانلاح 1971 قد اهنم بذللك وأعطى الأولوية للغة الوطنية، مع الحرص على على تلقينها

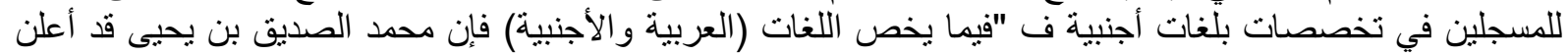

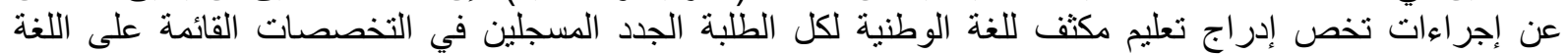

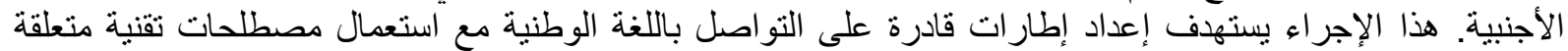

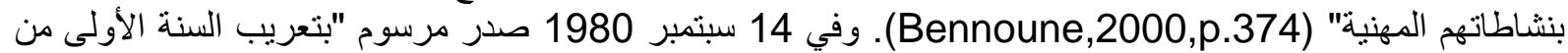

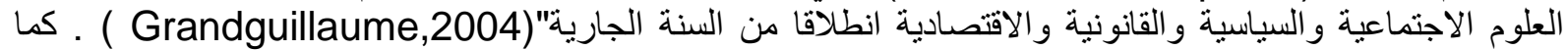

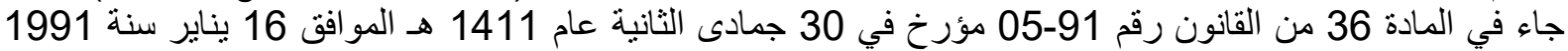

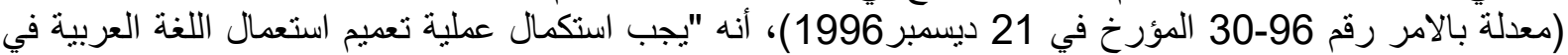

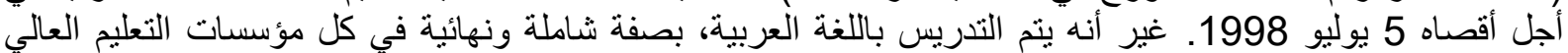

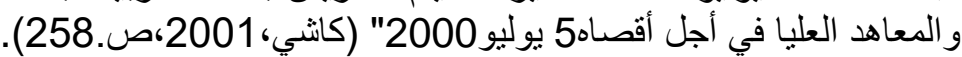

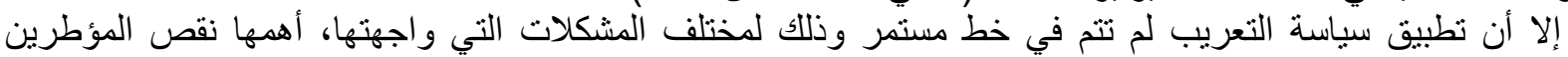

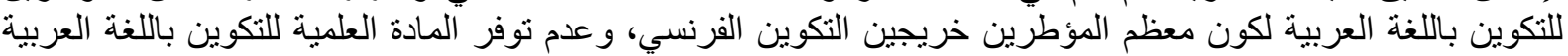

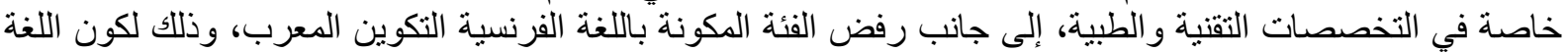

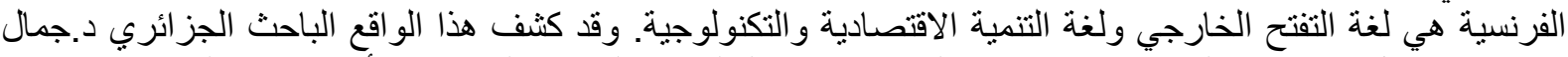

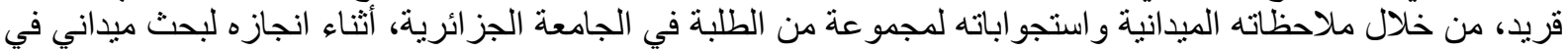
أو ائل السبعينيات وبحث آخر حول نفس الموضوع في بداية التسعينيات،لإجراء مقارنة بين أساتذة وطلبة كل جيل ونظام 
التكوين الجامعي عامة، وقد صرح أن "في بداية السبعينيات كان الطلبة المعربين حاملين لتصور للعالم بعكس المظاهر

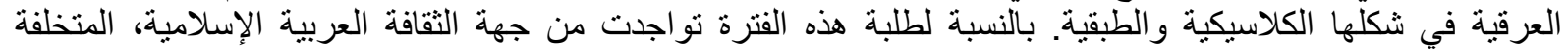

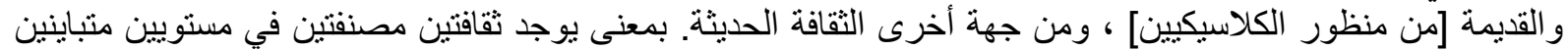

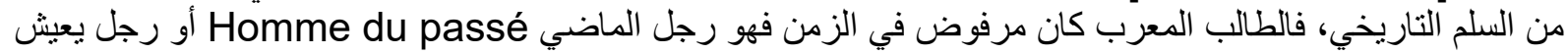

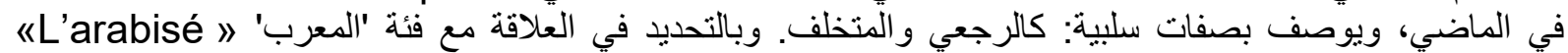

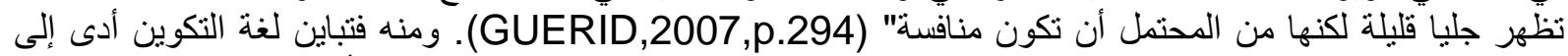

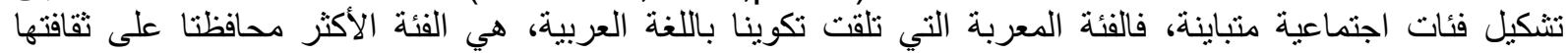

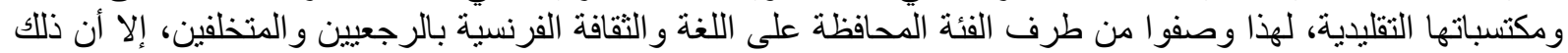

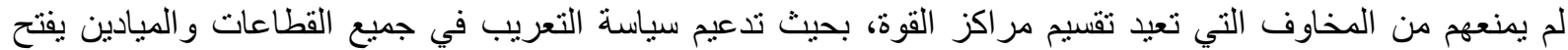
المجال للمعربين أن يحتلوا المكانة القيادية في المجتمع و التي كانت حكر التي على الفئة الفئ المفرنسة نتيجة التركة الاستعمارية

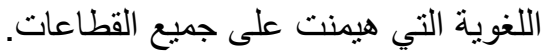
فبالنسبة لفئة الطلبة المكونين باللغة الفرنسية والتي صنفت في فئة الكلاسيكيين لأنهم الأقدم في مجال التكوين الجامعي

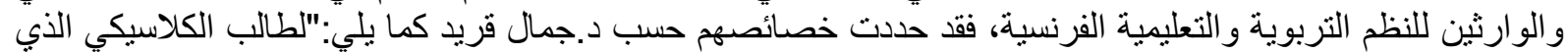

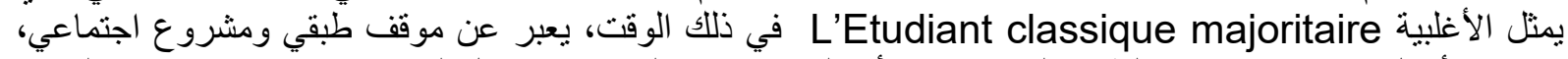

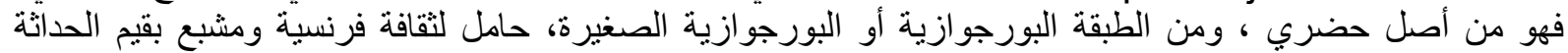

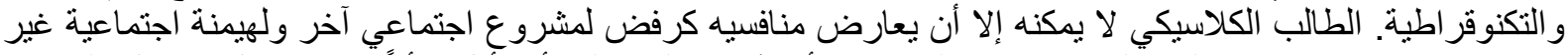

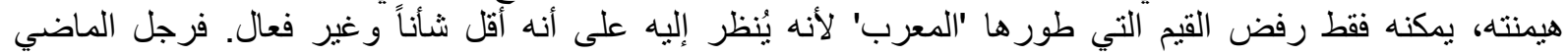

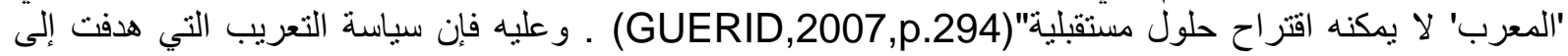
استكمال استرجاع السيادة الوطنية والقومية المحلية، قد ساهمت في تصنيف الطلبة الجامعيين الى فئتين الإنين متباينتين في

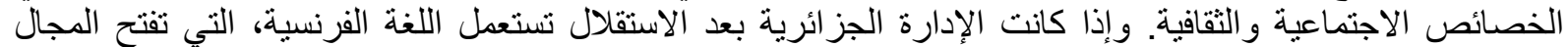

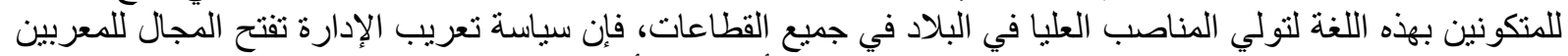

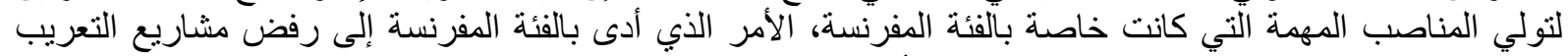

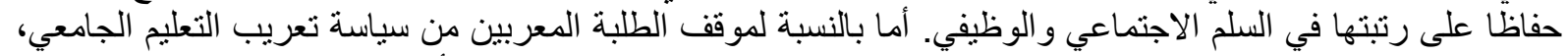

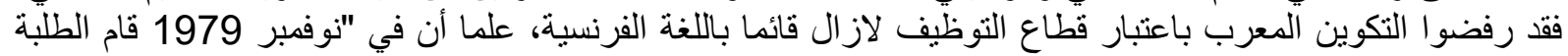

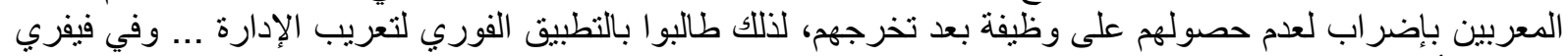

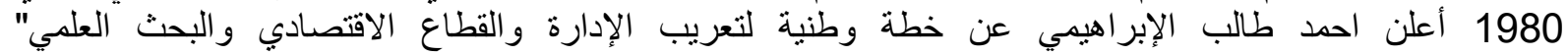

(Grandguillaume,2004)

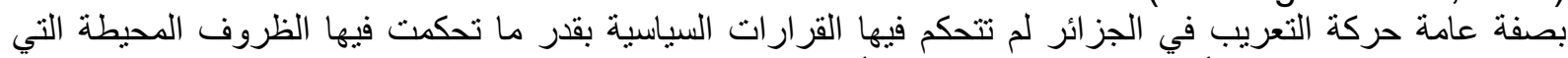

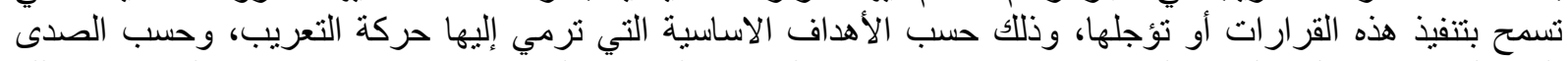

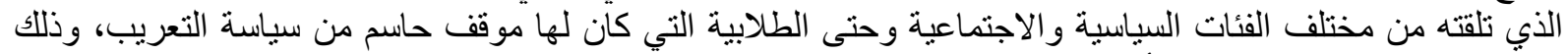

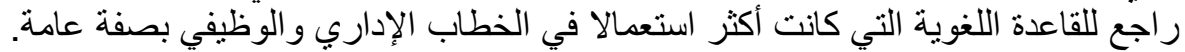

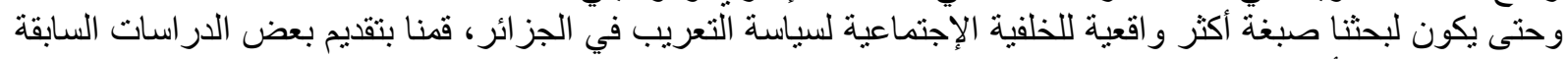

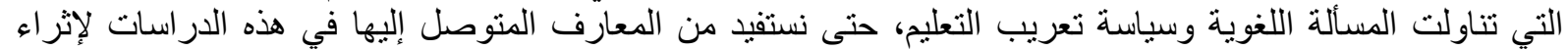

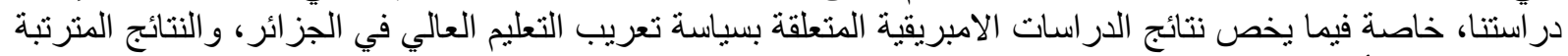

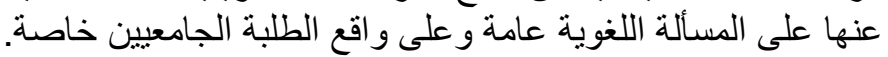
3. دراسات لغوية عرض وتحليل:

- Khaoula Taleb Ibrahimi, « L'école algérienne au prisme des langues de scolarisation » (Taleb Ibrahimi,2017, p.53-63) :

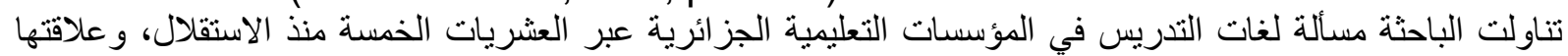

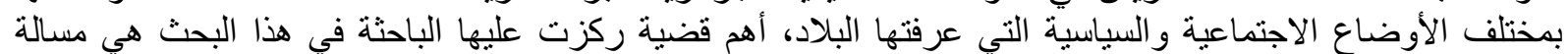

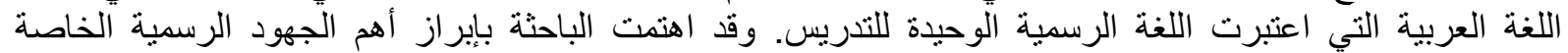

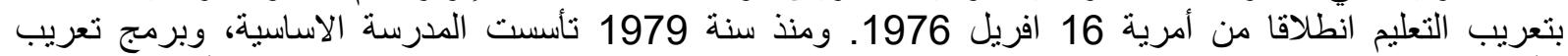

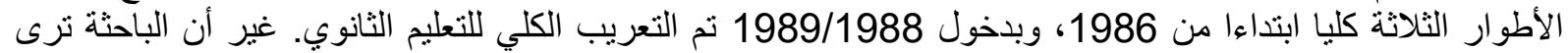

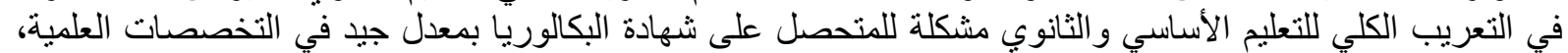

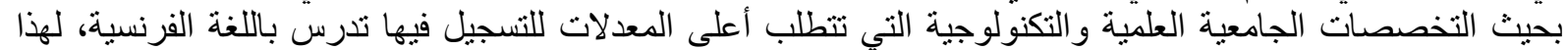

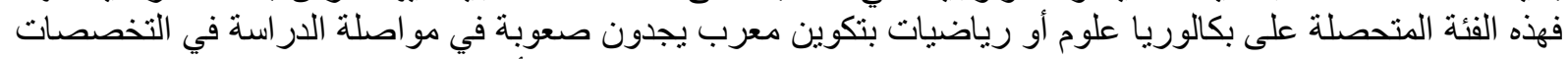

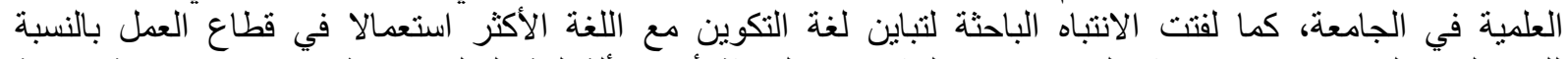

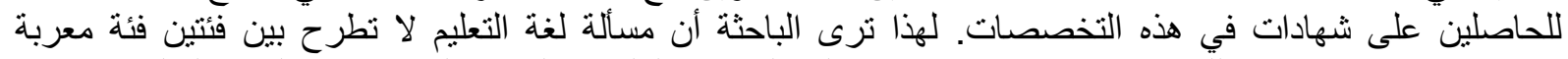

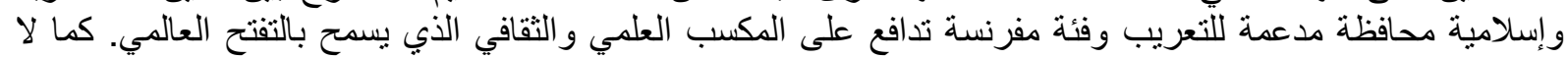




\section{THE POLICY OF ARABIZATION OF EDUCATION IN ALGERIA BETWEEN \\ LINGUISTIC PLANNING AND SOCIAL REALITY: ARABIZATION OF HIGHER EDUCATION AS A MODEL}

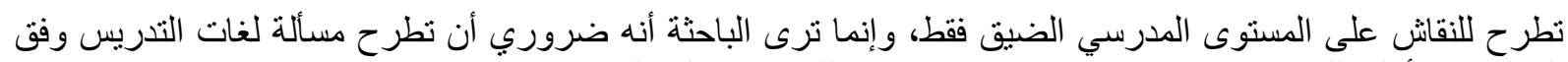

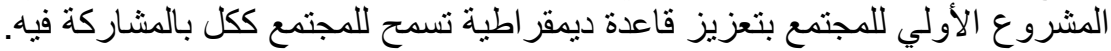

- Gilbert Grandguillaume, L'arabisation au Maghreb (Grandguillaume,2004, p.15-40) :

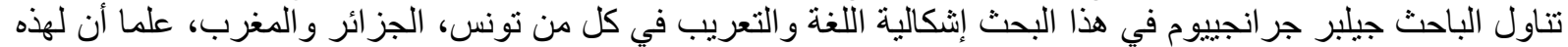

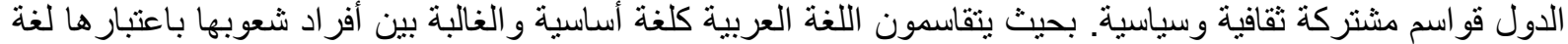

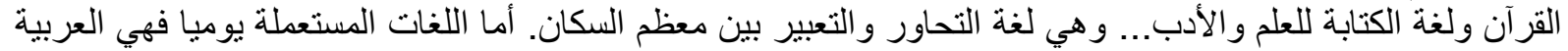

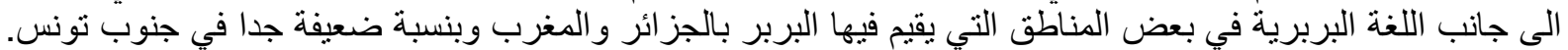
غير أن الاستعمار الفرنسي ادخل على هذه الدول اللغة الفرنسية كلغة أساسية في الإدارة الاستعمارية، والنفية وانتشر استعمالها

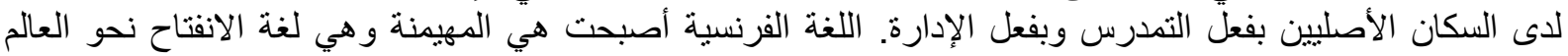

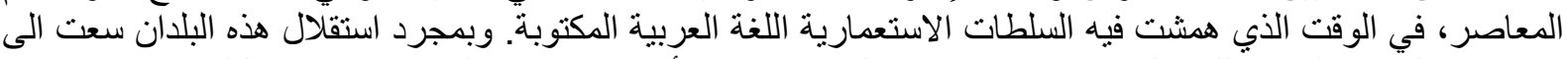

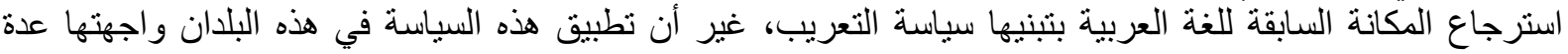

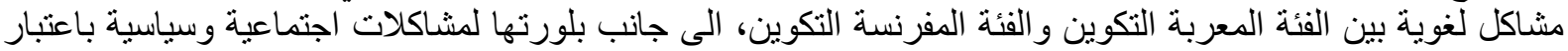

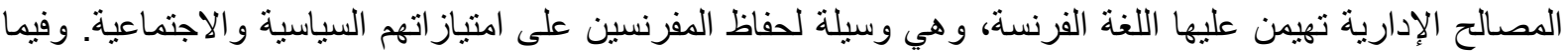

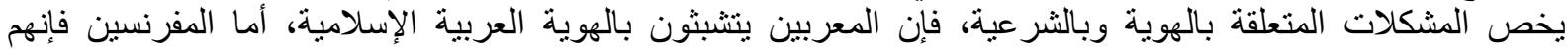

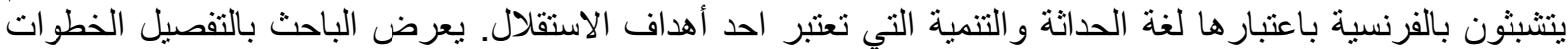

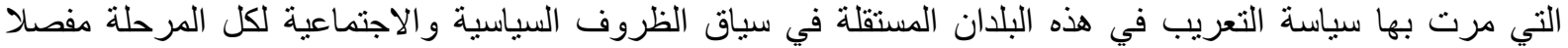

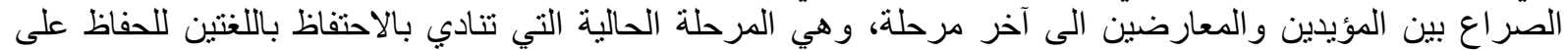

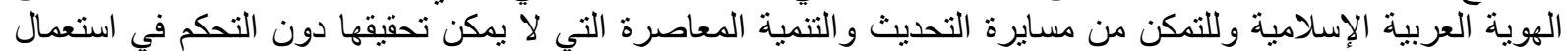
لغة أجنبية الني تعتبر مفتاح للتفتح العالمي.

- Keener, Lily, "Crise linguistique en Algérie: les conséquences de l'arabisation" (Keener,2019) :

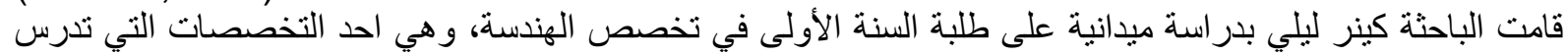

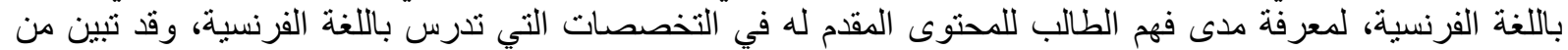
التحقيق الميداني انه فقط 35\% من الطلبة المزعوم أنهم مزدوجي اللغة (فرنسية وعربية) يفهمون الاسئلة المطروحة

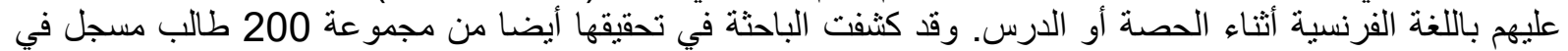
السنة الأولى هندسة، فإن 20 \% منهم قد صرحوا أنهم لا يفهمون إطلاقا اللغة الفرنسية مقابل 45 \% الذين الذين صرحوا أنهم

يفهمونها بمستوى متوسط. فتحقيق الباحثة قد كثف ضعف الطالب الجزائري في تحكمه في اللغة الفرنسية في التخصصات العلمية التي تدرس باللغنة

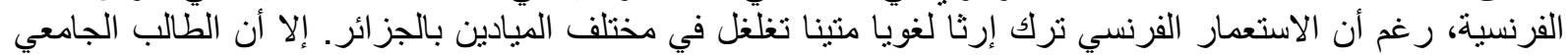

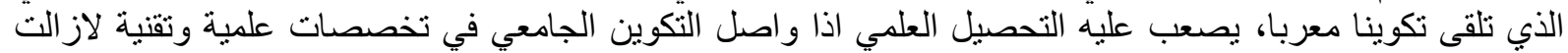

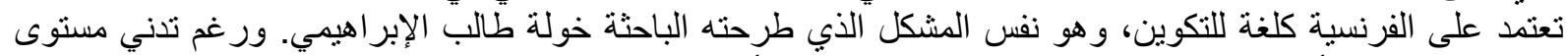

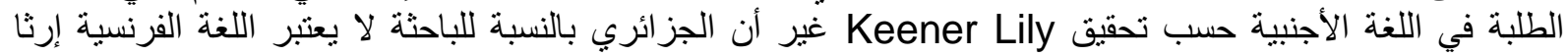

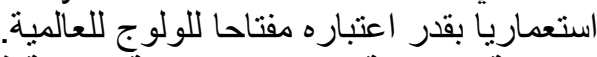

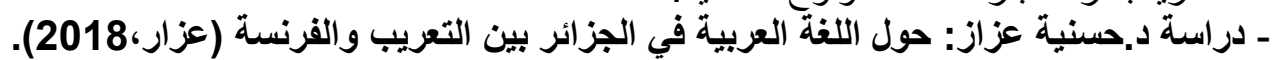

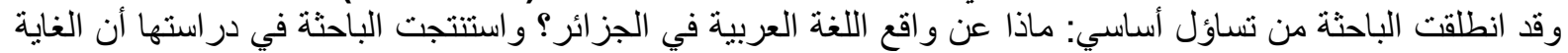

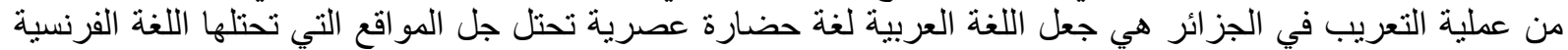

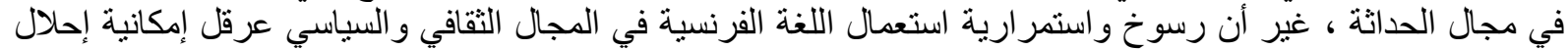

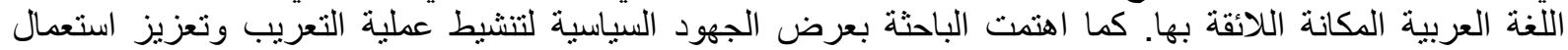

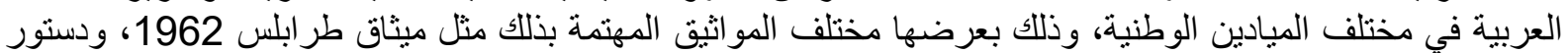

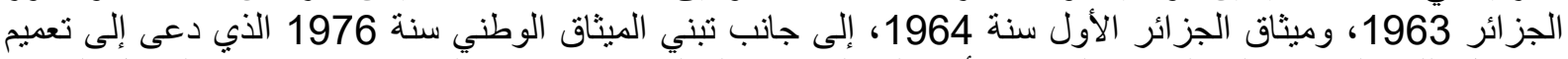

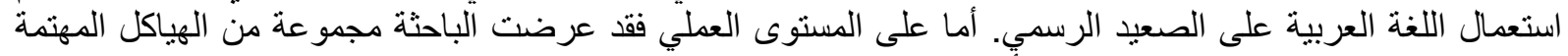

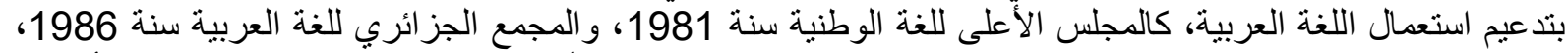

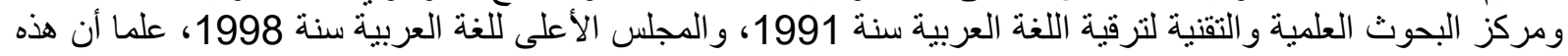
الهياكل عامة تهذف إلى خدمة اللغة العربية وترقيتها وتطوير اللىها، وتعميمها. 


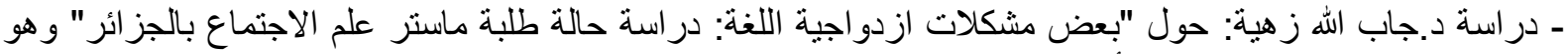

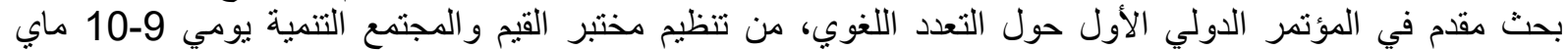

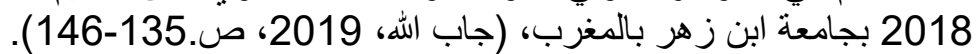

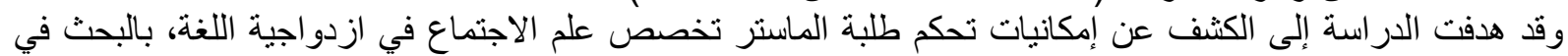

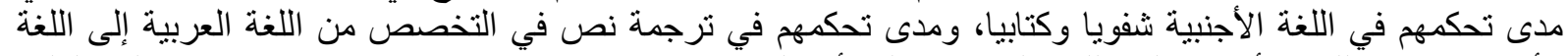

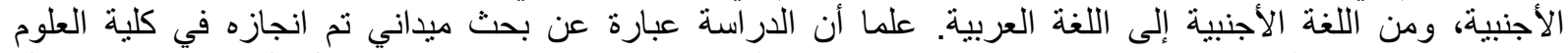

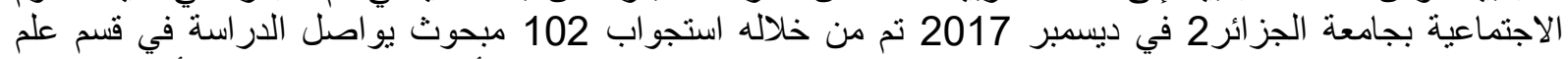

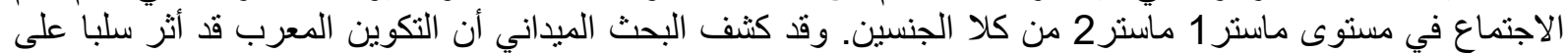

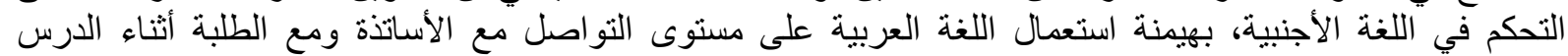

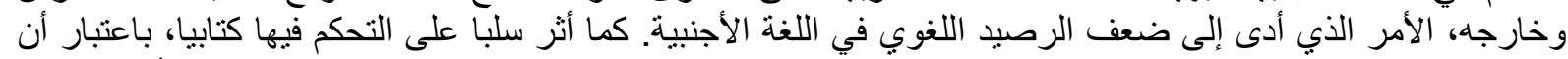

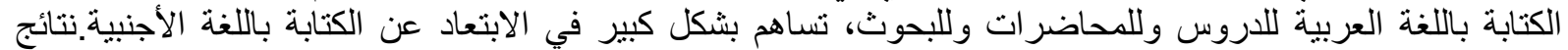

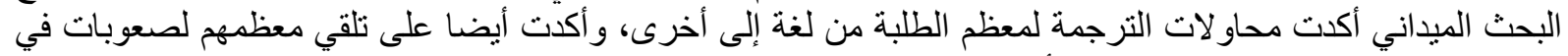

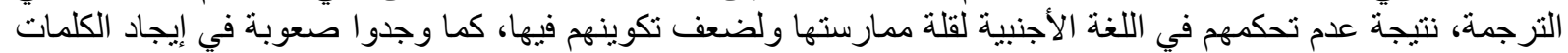

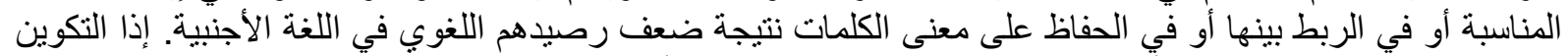

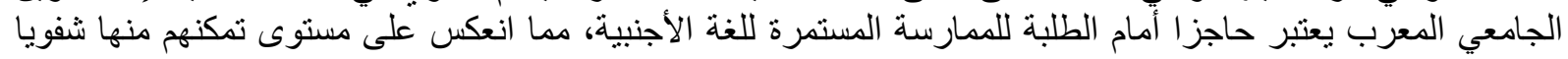

4. أنمعنايب على الاراسات اللغوية:

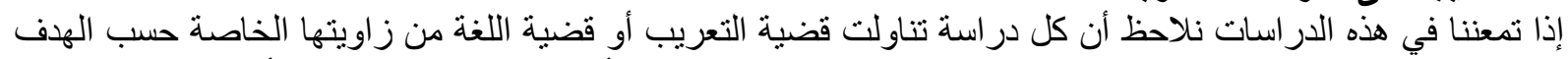

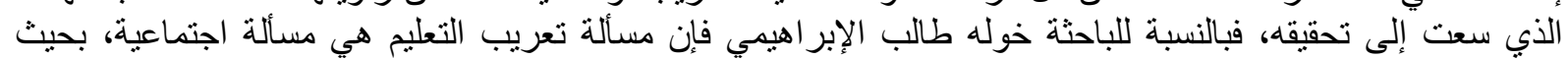

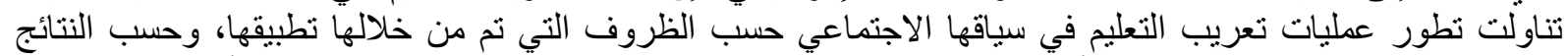

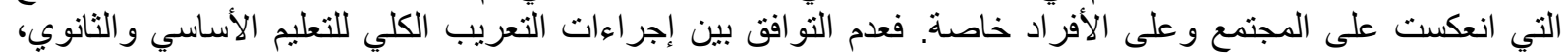

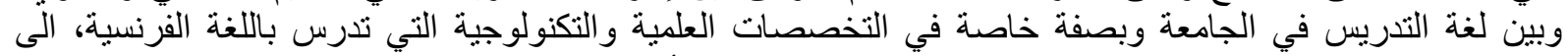

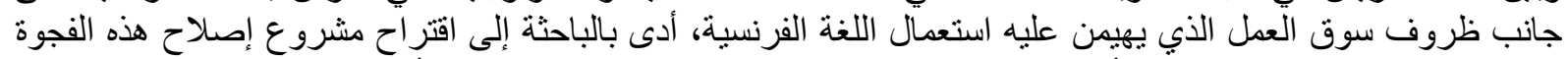

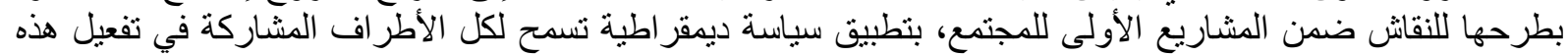

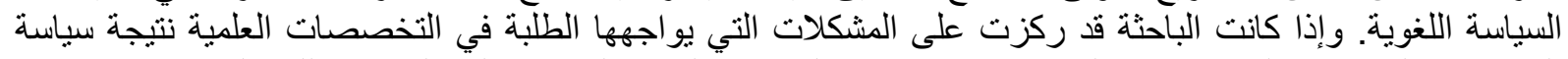

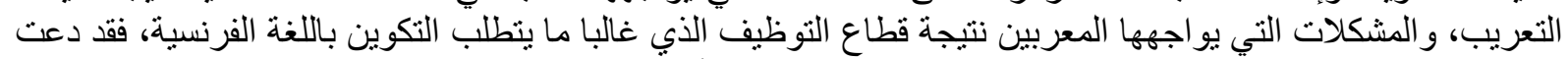

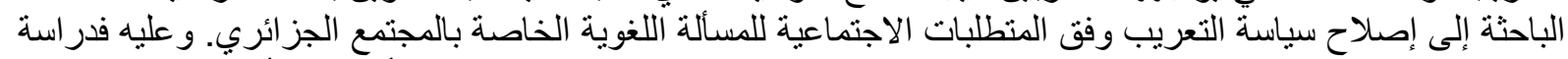

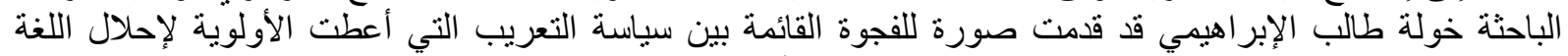

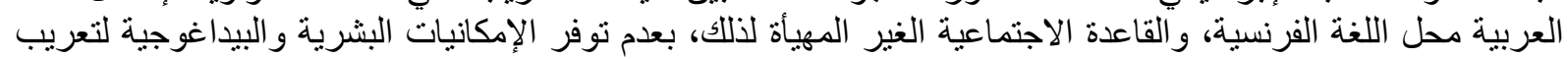

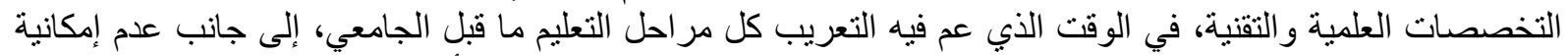

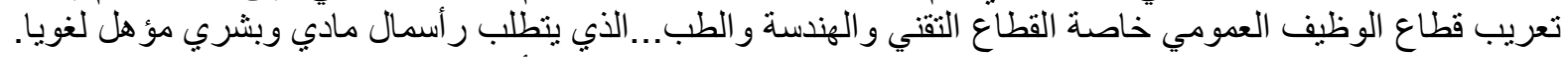

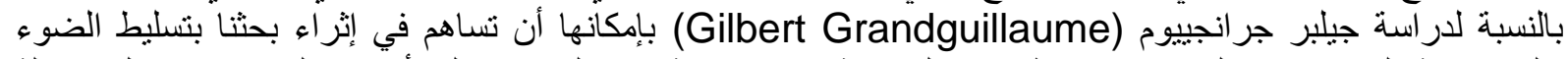

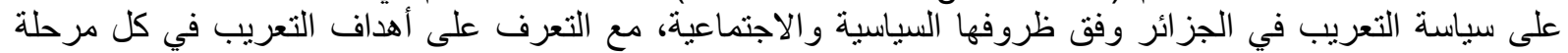

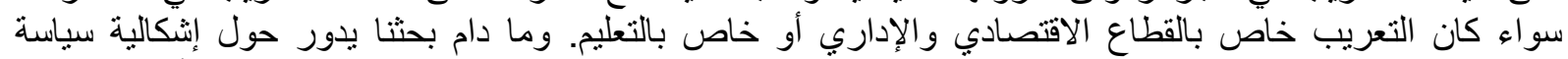

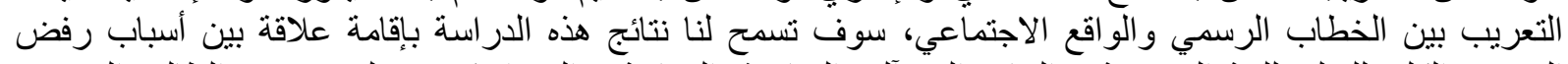

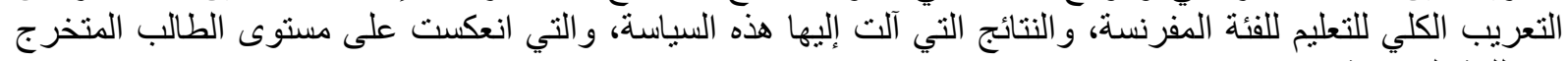
في اللغة الفرنسية. أمًا الباحثة كينر ليلي (Keener, Lily) فقد قدمت در اسة ميدانية تعكس مستوى التحكم في اللغة الفرنسية لطلبة سنة أولى في

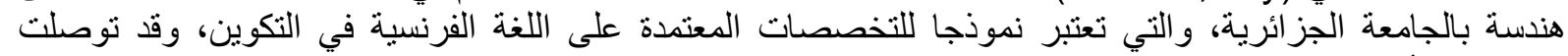

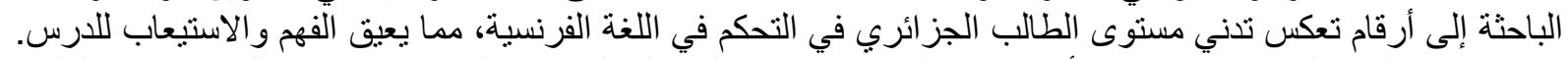

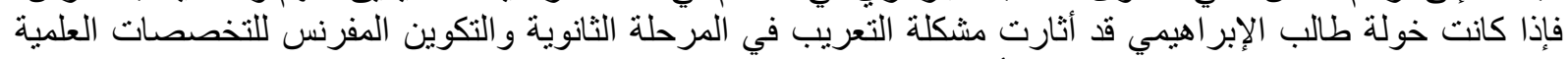

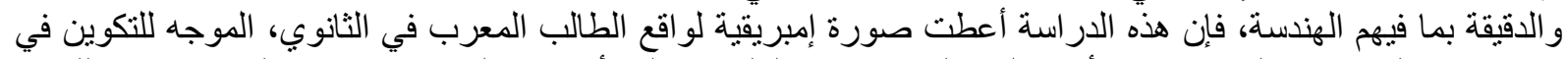

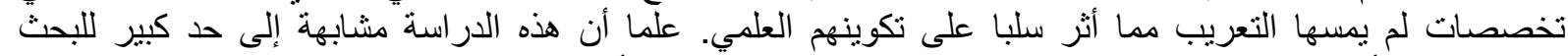

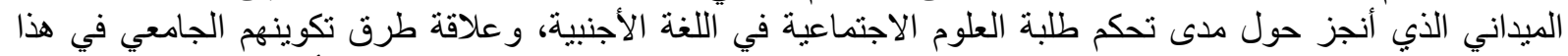

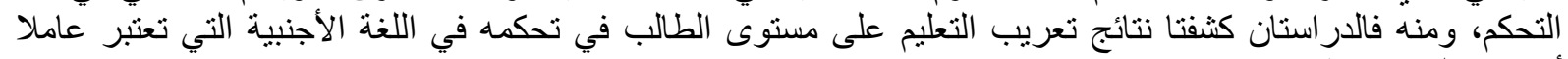

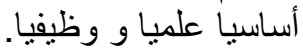

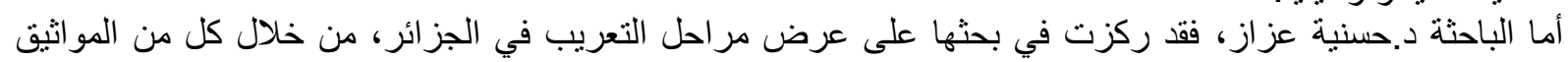

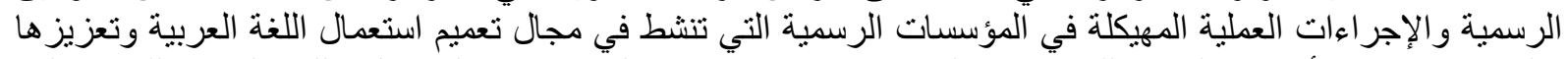

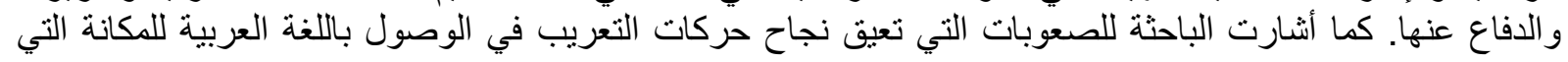




\section{THE POLICY OF ARABIZATION OF EDUCATION IN ALGERIA BETWEEN \\ LINGUISTIC PLANNING AND SOCIAL REALITY: ARABIZATION OF HIGHER EDUCATION AS A MODEL}

تستحقها، وذلك لتغلغل اللغة الفرنسية في النسيج الثقافي و السياسي بشكل عميق. علما أن هذه الدربة استة قد أثرت الثرت بحثنا بمعطيات نظرية حول الجهود الرسمية ألمبذولة لتعزيز استعمال اللغة العربية، إلى درجة فئنة فقدان الطالب الجامعي التحكم في الازدواجية اللغوية في التكوين.

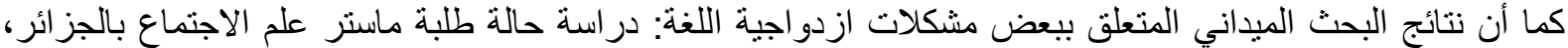

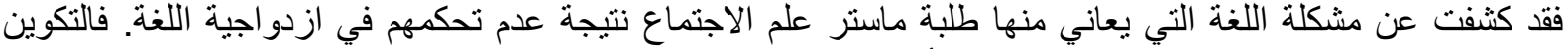

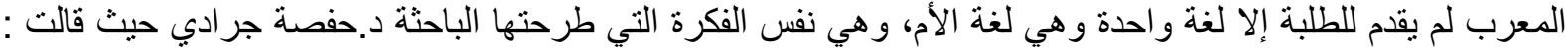

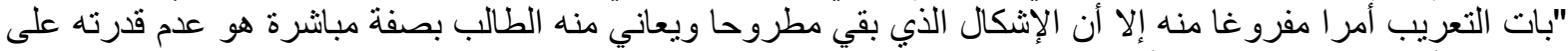

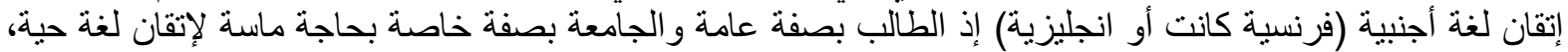

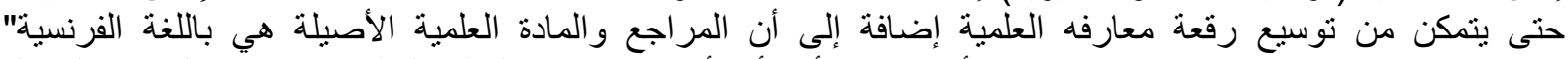

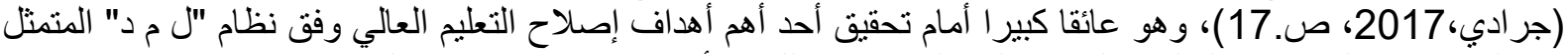

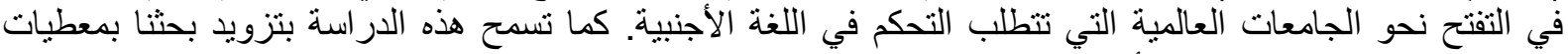

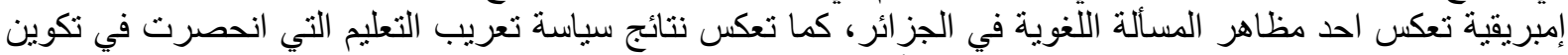

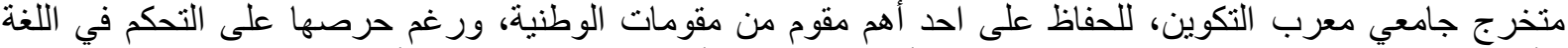

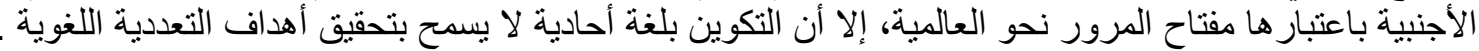

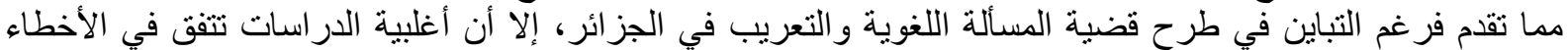

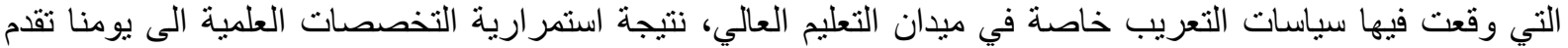

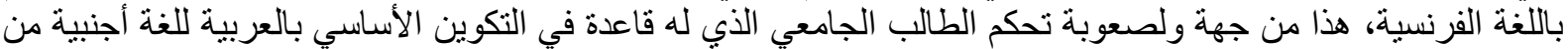

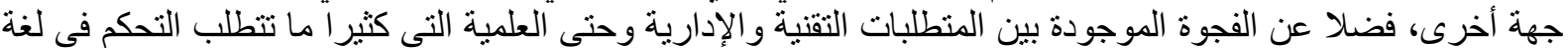

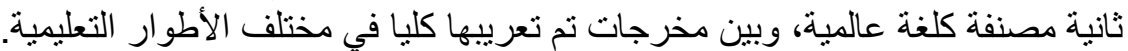

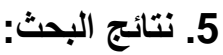

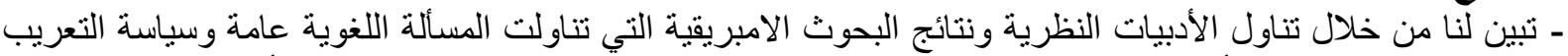

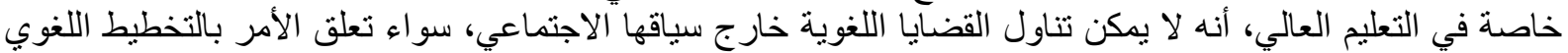

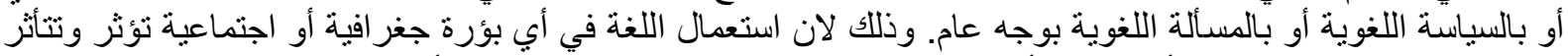

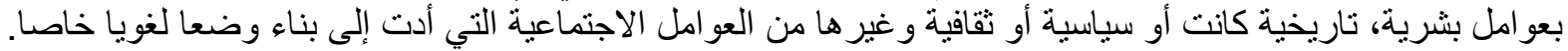

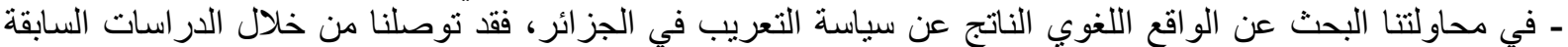

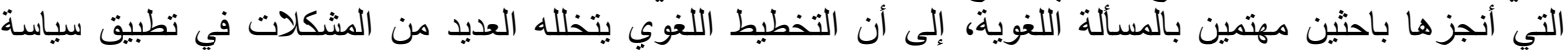

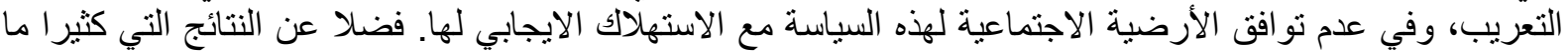

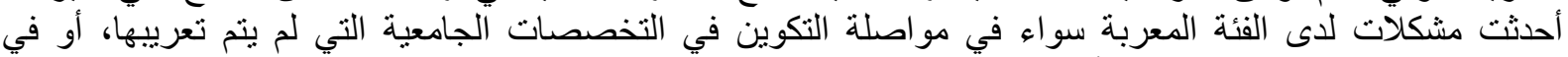
توظيف الثريحة التي تفقت للغة الأجنبية المطلوبة في سوق العمل نتيجة التكوين المعرب الذي تلقوه عبر كل مراحل

التكوين.

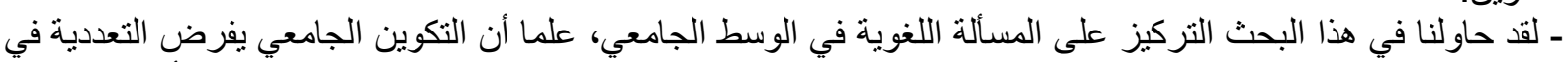

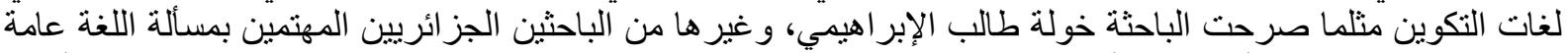

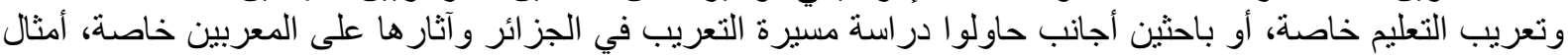
الباحثة كريستيان سوريو (Christiane Souriau) و الباحث جيلبر جرة النجييوم (Gilbert Grandguillaume)

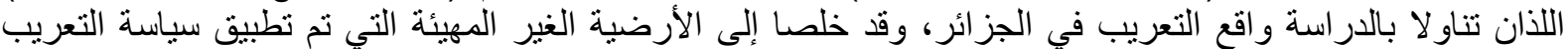

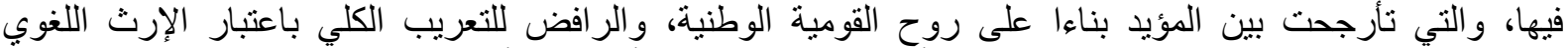

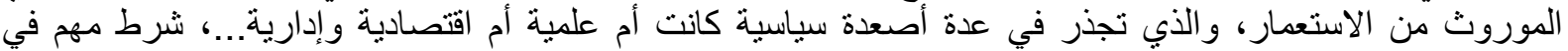
تحقيق التنمية البشرية والاقتصادية، كما أنه عامل مهم لمسايرة التطور العالمي في جميع المجالاتية العاته باعتبار الفرنسية هي

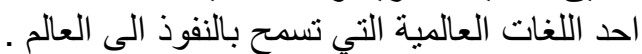

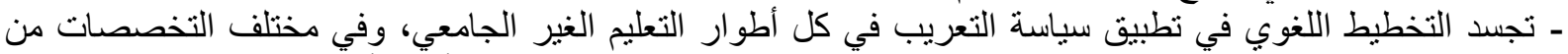

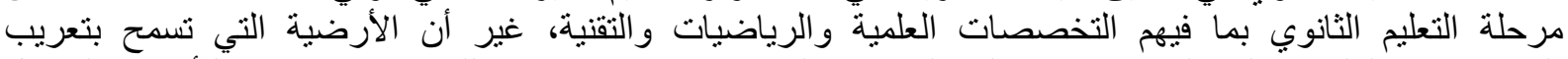

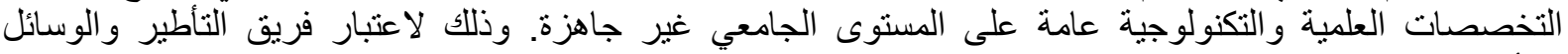

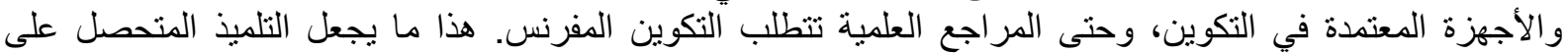

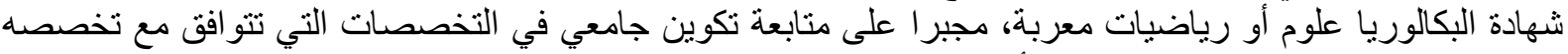

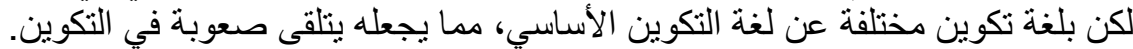


ـ ومن جهة أخرى فإن البحث الإمبريقي الذي ثم في كلية العلوم الاجتماعية بجامعة الجزائر، قد بين أن التكوين المعرب

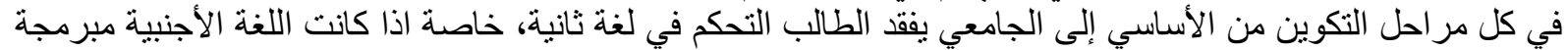

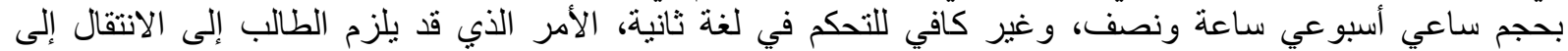

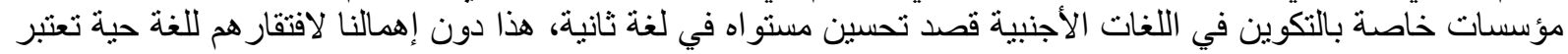

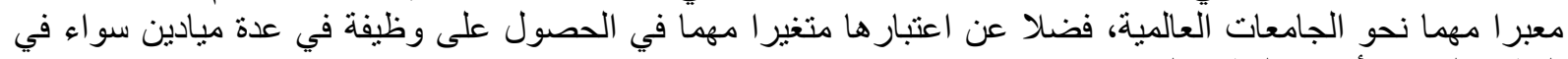
القطاع الخاص أو في القطاع العمومي.

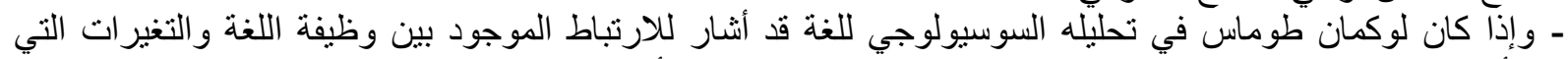

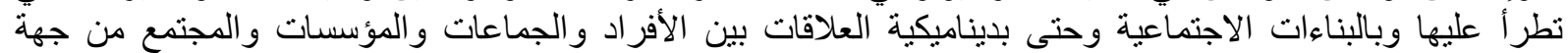

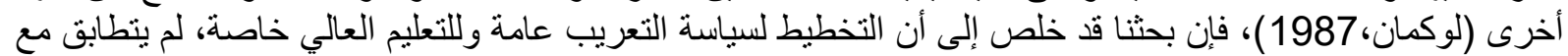

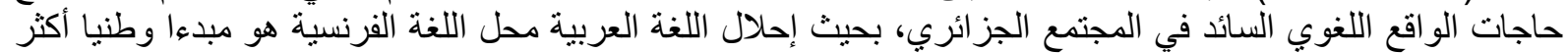

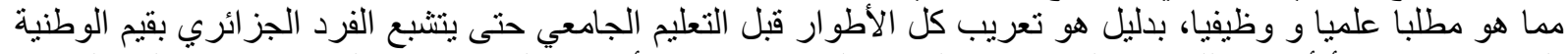

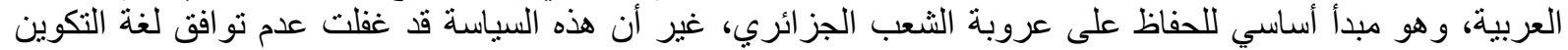

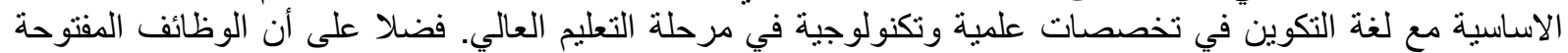

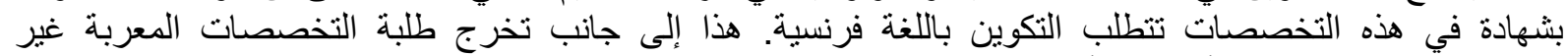

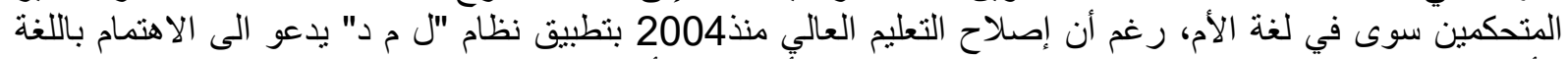

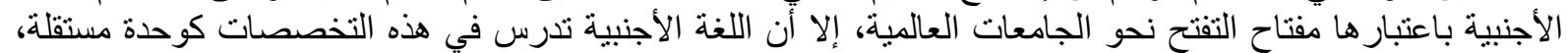

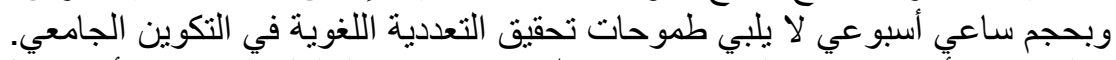

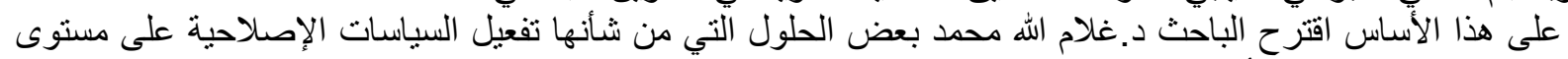

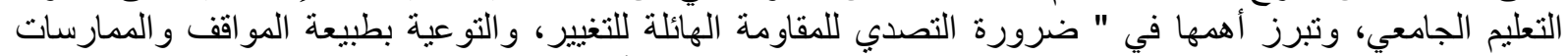

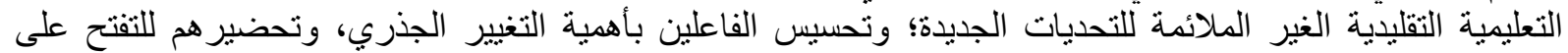

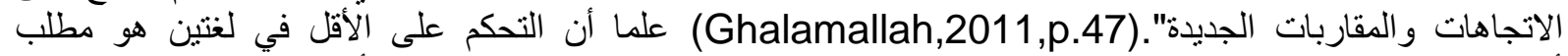

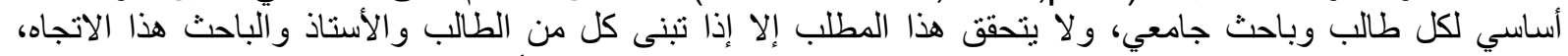

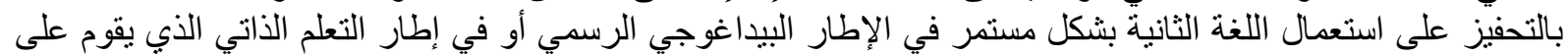

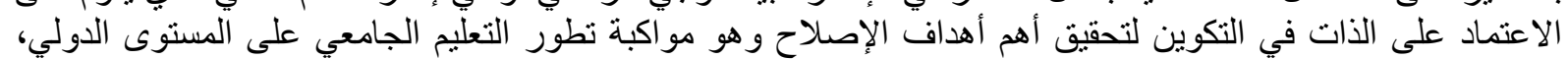

و الذي يتحقق بالتمكن من اللغة الوطنية واللغات الألغنية الأنية.

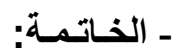

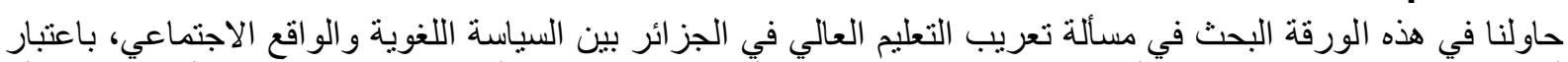

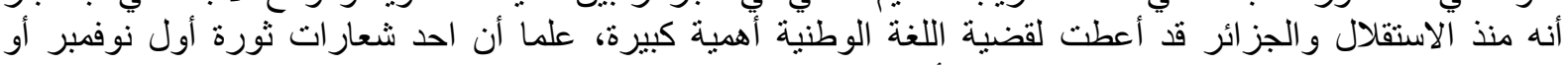

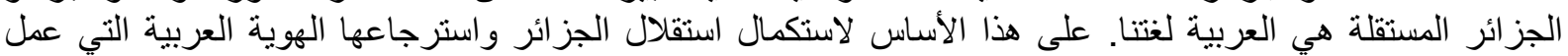

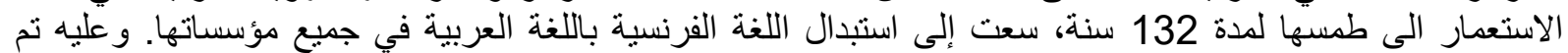

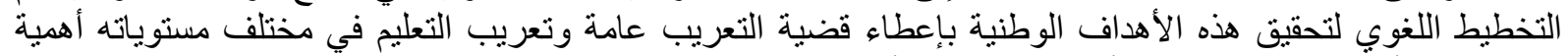

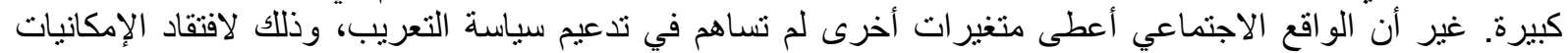

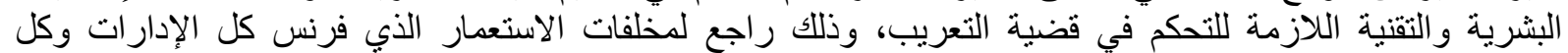

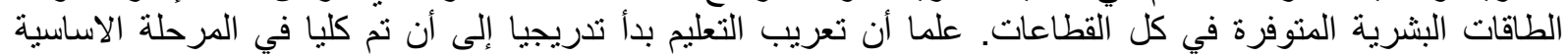

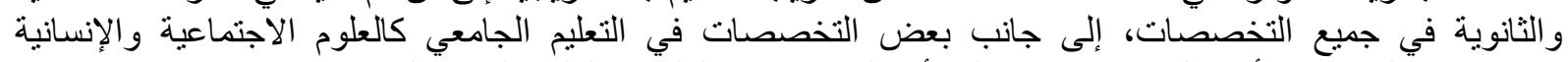

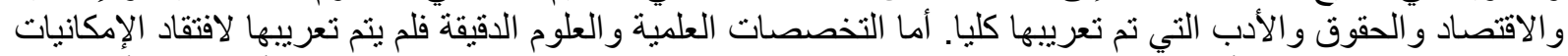

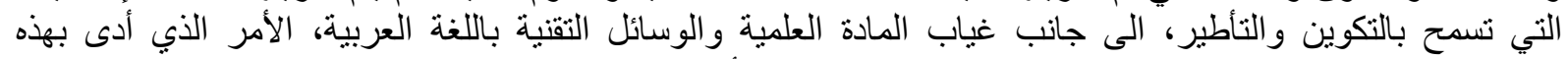

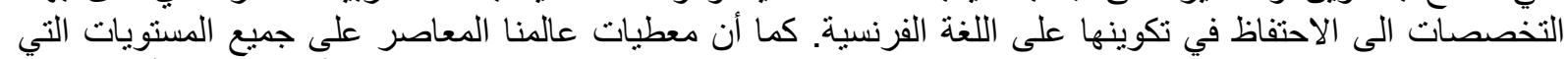

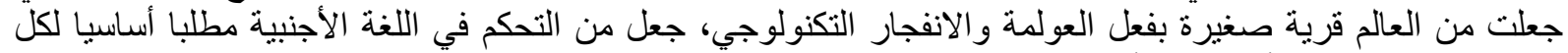

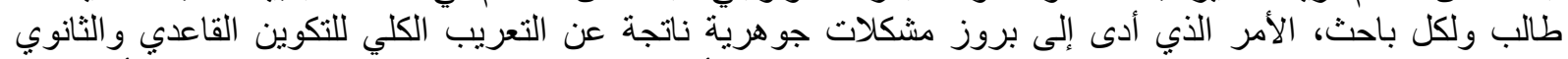

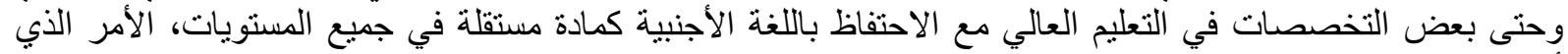

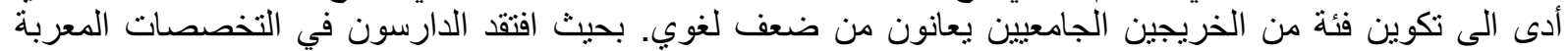

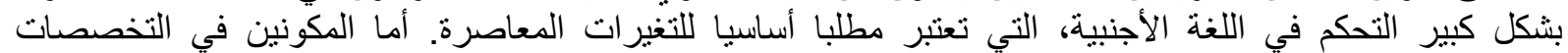

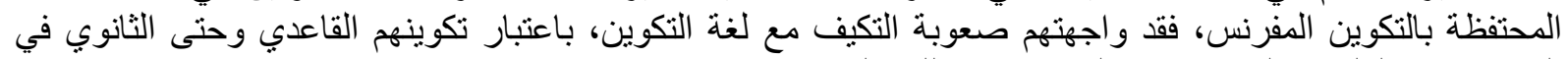
التخصصات العلمية و الرياضيات و التقنية قد نم باللغة العربية. 
ـ التوصيات: إنكالية التخطيط اللغوي في الجزائر تحتاج لإعادة النظر فيها حتى ينم تكوين مخرجات متحكمة في لغة الغئة

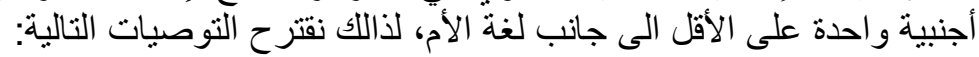

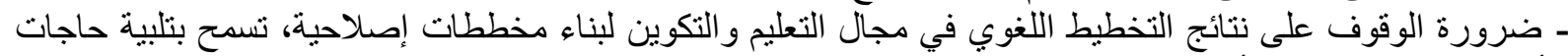
الأفر اد في التحكم على الأقل في لغنتين.

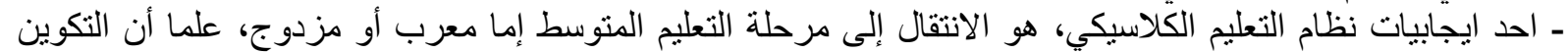
المزدوج يدمج في التكوين وحدات تدرس باللغة الأجنبية الى جانب وحدة اللغية اللغة الأجنبية كوحدة مستقلة، وذللك لتمكين الطلبة منذ المراحل الأولى من التعليم من استعمال لغتين في التئ التكوين.

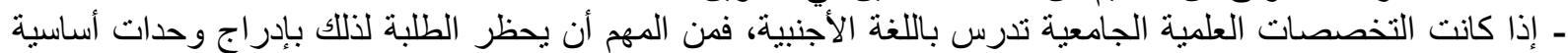

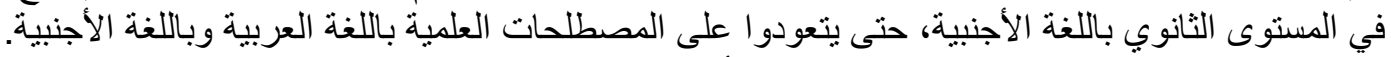

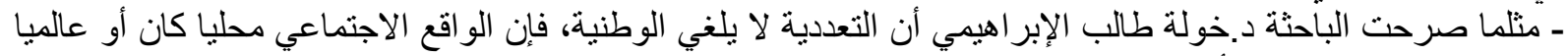

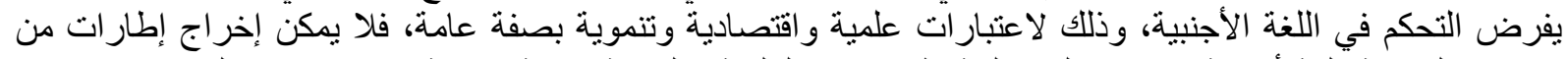

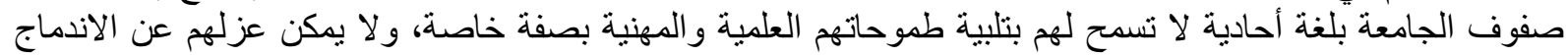
الايجابي مع تغيرات العصر التي تنظلب مهار لات لغوية لغية وعلمية وحتى تكنولوجية.

$$
\text { بن سيف الغتامي، س.جع: (2002 ). التعريب ودوره في جودة التعليم العالي، ص3، استرجعت من الموقع: }
$$

https://www.alarabiahconferences.org/wpcontent/uploads/2019/04/conference_research-1457675600-15277602112002.pdf

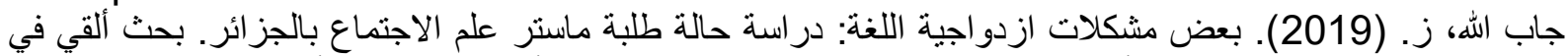

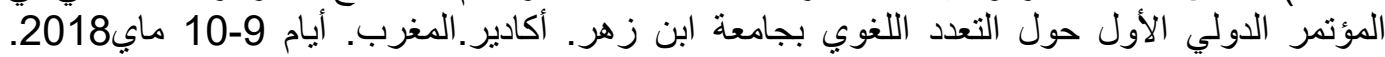
ص136-136. (2017)

جر ادي، ح. (2017). رؤية لسياسة التعريب في الجزائر. مجلة العلوم الإنسانية والاجتماعية. العدد 28. جامعة ورقلة. ص 20-9. استرجعت من الموقع:

https://revues.univ-ouargla.dz/index.php/numero-28-mars-2017-ssh/3759-2017-05-

03-09-43-25

شطة،م. (2017).المسألة اللغوية في الجزائر. مو اقف و أفكار خولة طالب الإبراهيمي نموذجا، مجلة المقري للار اسات

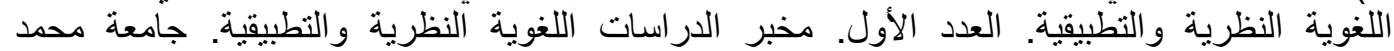

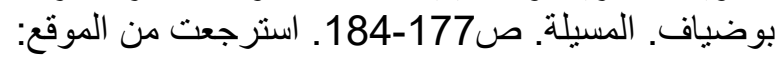

http://dspace.univ-msila.dz:8080/xmlui/handle/123456789/5275

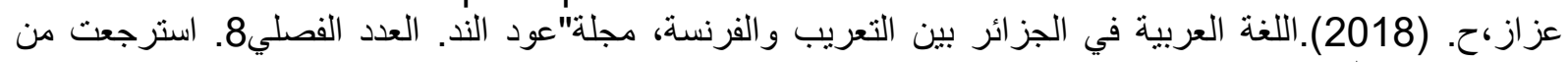

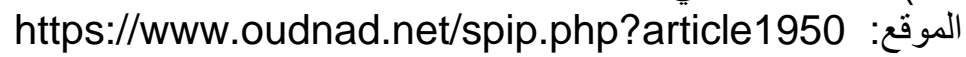

كاشي، ب. (2001). وجوب تعميم استعمال اللغة العربية في قوانين الجمهورية الجزائرية. مجلة الجية اللغة العربية. المجلد3

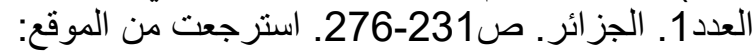

http://www.webreview.dz/IMG/pdf/_10.pdf

لوكمان، تَ.(1987). علم اجتماع اللغة( أ. باقادر، المترجم). جدة: النادي الأدبي الثقافي. (العمل الأصلي نشر سنة .(1962

BENNOUNE, M. (2000). Education Culture et Développement en Algérie : Bilan perspectives du système éducatif. Algérie: Editions Marinoor-ENAG. p.374

Ce que signifie l'arabisation.(1965). le monde diplomatique .p.16

URL : https://www.monde-diplomatique.fr/1965/10/A/26897

GHALAMALLAH, M .(2011). L'Université algérienne et sa gouvernance. Alger : CREAD.

GRANDGUILLAUME, G. (2004). L'ARABISATION AU MAGHREB, Revue d'Aménagement linguistique, Aménagement linguistique au Maghreb. 
Office Québécois de la langue française. N¹07. Quebec. p.15-40. URL : http://ggrandguillaume.fr > photo > Québec2004.doc

GUERID, D.(2007). L'exception algérienne: la modernisation à l'épreuve de la société. Alger. CASBAH Editions.

KEENER, L. (2019). Crise linguistique en Algérie: les conséquences de l'arabisation. Senior Capstone Theses. 36.

URL:https://scholarworks.arcadia.edu/cgi/viewcontent.cgi?article=1040\&context=seni or_theses\#: :text=A\%20cause\%20de\%20cette\%20politique,qualit\%C3\%A 9\%20limit\%C3\%A9e\%20dans\%20ces\%20langues.

SOURIAU, C. (1977). LA POLITIQUE ALGÉRIENNE DE L'ARABISATION. A propos de la 1ère conférence nationale de l'arabisation à Alger (14-17 mai 1975). Institut de recherches et d'études sur les mondes arabes et musulmans. IREMAM - UMR 7310 - CNRS/Aix Marseille Université. P. 375-397

URL : https://books.openedition.org/iremam/141 ?lang=fr

TALEB IBRAHIMI, K., L'Ecole algérienne au prisme des langues de scolarisation. Revue internationale d'éducation de Sèvres [En ligne]. 70 | 2015, mis en ligne le 01 décembre 2017, p.53-63.

URL : http://journals.openedition.org/ries/4493 ; DOI : 10.4000/ries.4493 